\title{
AVALIAÇÃO DO EXTRAdO DA SEMENTE DO MARACUJÁ (Passiflora edulis Sims) OBTIDO POR EXTRAÇÃO COM DIÓXIDO DE CARBONO SUPERCRÍTICO: INFLUÊNCIA DO EMPREGO DE COSSOLVENTE
}

\author{
J. B. CANOZZI ${ }^{1}$, A. BOLZAN ${ }^{1}$ \\ ${ }^{1}$ Universidade Federal de Santa Catarina, Departamento de Engenharia Química e Engenharia de \\ Alimentos \\ E-mail para contato: jbcanozzi@hotmail.com.br
}

\begin{abstract}
RESUMO - As sementes do maracujá são um subproduto da indústria de alimentos, o Brasil é responsável por $90 \%$ da produção mundial de maracujá, fruto que movimenta os mercados nacional e internacional. A extração supercrítica com $\mathrm{CO}_{2}$ é um método ambientalmente favorável de separação empregado como alternativa aos métodos tradicionais, que envolvem solventes orgânicos, e por sua vez é controlado pela combinação dos parâmetros pressão e temperatura. Cossolventes são freqüentemente utilizados para modificar as características dos solventes beneficiando processos da indústria química. No presente trabalho foram conduzidas extrações com emprego de $\mathrm{CO}_{2}$ supercrítico para a obtenção do extrato da semente de maracujá com e sem o emprego de co-solventes variando as condições de pressão (250 e 300 bar) e temperatura (55,60 e 70 $\left.{ }^{\circ} \mathrm{C}\right)$. Para todas as extrações foram alcançados rendimentos superiores a $20 \%$. Embora a influência dos parâmetros pressão e temperatura tenha demonstrado alta complexidade sobre o processo, o etanol se mostrou uma ótima alternativa como cossolvente para aceleração das extrações, reduzindo significativamente o tempo para obtenção do extrato sem alterar as propriedades do perfil de triglicerídeos observado. O maior rendimento obtido sem adição de modificador foi $23,97 \%$ a 250 bar e $60{ }^{\circ} \mathrm{C}$ decorridos 330 minutos enquanto a adição do modificador conduziu ao rendimento de $23,88 \%$ a 300 bar e $55^{\circ} \mathrm{C}$ no tempo de 120 minutos. O perfil de triglicerídeos do óleo da semente do maracujá foi determinado por cromatografia gasosa.
\end{abstract}

\section{INTRODUÇÃO}

O maracujá (Passiflora edulis) é um fruto originário da América Tropical, mais precisamente do Brasil. Atualmente é cultivado em larga escala nos trópicos, regiões subtropicais e temperadas incluindo este país, tanto que este é o maior produtor de maracujá-amarelo, respondendo por $90 \%$ da produção mundial. Seu suco pode ser consumido em sua forma natural, ou na forma industrializada, sendo a segunda o objeto de maior interesse econômico associado a esse fruto: seu suco na forma concentrada (Ferrari et. al., 2004). As sementes do maracujá por sua vez constituem um subproduto desta indústria. Estudos sobre a composição do óleo presente nas sementes do maracujá (Passiflora 


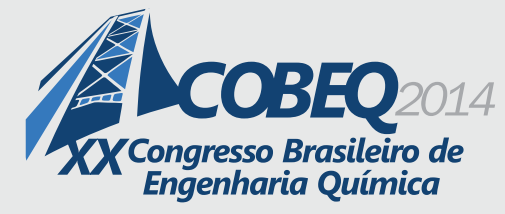

19 a 22 de outubro de 2014

Florianópolis/SC

edulis, Passiflora edulis f. flavicarpa e passiflora foetida) revelaram a presença de 22 a $28 \%$ de óleo na semente composto pelos seguintes ácidos graxos: linoléico (55- 66 \%), oléico (18-20\%), palmítico (10-14 \%) e linolênico (0,8-1,1\%), apesar de em menor proporção. Avaliando a composição revelada pelo estudo das sementes do maracujá, estas se mostram uma ótima alternativa para o emprego na alimentação humana (Jorge e Kobori, 2005; Canozzi, 2013).

Os óleos vegetais são comumente extraídos por métodos convencionais, como pressão mecânica ou emprego de solventes orgânicos. A aplicação de força mecânica pode deixar presente na matéria vegetal boa parte do óleo a ser extraído, resultando em baixos rendimentos apesar de proporcionar óleo com alta qualidade. Por outro lado, a extração com solventes orgânicos pode alterar as características do óleo devido a interações físico-químicas entre soluto-solvente.

A extração com fluidos supercríticos (ESC) é uma técnica de separação que geralmente emprega o dióxido de carbono $\left(\mathrm{CO}_{2}\right)$ como solvente no seu estado supercrítico $\left(\mathrm{Tc}=32{ }^{\circ} \mathrm{C}\right.$. $\mathrm{Pc}=74$ bar) e tem sido amplamente estudada como alternativa a métodos tradicionais para obtenção de extrato por apresentar bons rendimentos e preservar as características físico-químicas do extrato. $\mathrm{O}$ $\mathrm{CO}_{2}$ é um solvente de baixo custo, alta disponibilidade, atóxico, não inflamável e permite ainda a fácil separação do extrato do solvente ao fim da extração, por isso sua ampla utilização (Liu et. al., 2009). A eficiência do processo de extração supercrítica depende, principalmente, do poder solvente do $\mathrm{CO}_{2}$. Entretanto, este solvente possui baixa polaridade, o que pode ser modificado pela adição de solventes orgânicos, desde que apresentem polaridades superiores. Assim, é possível adequar as propriedades do solvente a fim de aperfeiçoar a extração.

\section{MATERIAL E MÉTODOS}

\subsection{Materiais e Preparo das Amostras}

Maracujá (Passiflora edulis) in natura da marca Trombini, classificação Super, foi adquirido no CEASA de São José (SC). As sementes foram separadas da casca e da polpa manualmente e secas em estufa com circulação e renovação de ar Marconi, modelo MA 03515 por 24 horas a $50{ }^{\circ} \mathrm{C}$, após foram trituradas em liquidificador doméstico e armazenadas em pote de vidro com tampa plástica, envoltos por papel alumínio mantidos em geladeira a temperatura de $4{ }^{\circ} \mathrm{C}$. Dióxido de Carbono da marca Linde, pureza mín. 99,9\% foi utilizado como solvente e empregado na fase se evaporação do cossolvente ao final das extrações. Álcool etílico P.A. da marca Vetec $\left(\rho=0,790 \mathrm{~kg} / \mathrm{m}^{3}\right.$ a $\left.20{ }^{\circ} \mathrm{C}\right)$ foi empregado como cossolvente.

\subsection{Unidade de Extração}

As extrações a altas pressões foram realizadas no Laboratório de Controle de Processos do departamento de Engenharia Química e de Engenharia de Alimentos da Universidade Federal de Santa Catarina, campus Trindade, Florianópolis, SC, como parte do em um sistema de extração supercrítica (ESC) da marca Jasco, conforme mostra Figura 1. 


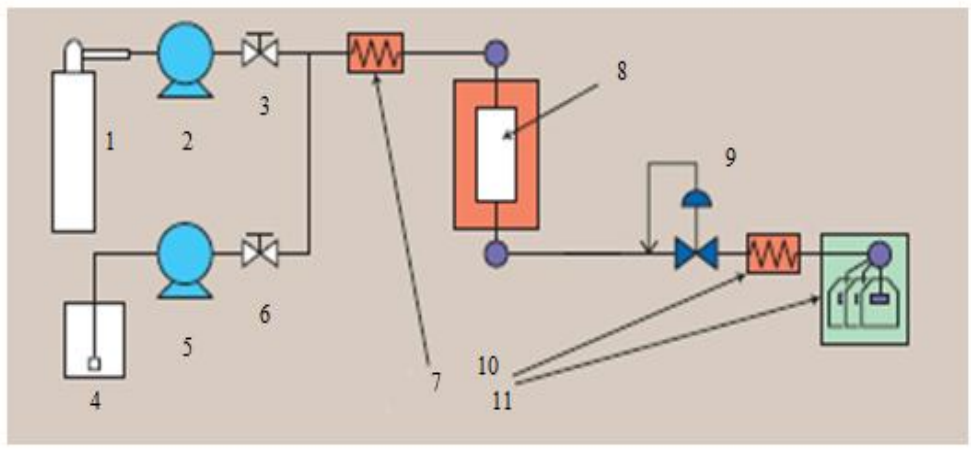

1. Cilindro de dióxido de carbono

2. Bomba de dióxido de carbono

3,6. Válvulas de controle de fluxo

4. Recipiente contendo cosolvente

5. Bomba de cosolvente

\begin{abstract}
7,10. Controladores de temperatura 8. Vaso de Extração envolvido pelo formo para controle da temperatura 9. Válvula Backpressure

11. Recipiente para coleta de amostra
\end{abstract}

Figura 1 - Esquema do sistema de extração supercrítica.

Antes do início de cada extração o vaso extrator foi lavado com água e detergente, enxaguado com água e posteriormente com álcool, seco com ar comprimido e pesado em balança digital semianalítica (KN500, Digimed, Brasil). Uma vez seco, o volume total do vaso extrator $(10 \mathrm{~mL})$ foi completado com a matriz vegetal já preparada e novamente pesado na mesma balança. $\mathrm{O}$ vaso extrator foi conectado ao sistema ESC e aguardado o tempo necessário para o forno alcançar a temperatura desejada. Quando alcançada a temperatura de trabalho, foi aberta a válvula de $\mathrm{CO}_{2} \mathrm{e}, \operatorname{nos}$ casos do emprego do cossolvente, também a válvula do cossolvente, permitindo o fluxo dos solventes para o interior do vaso de extração, promovendo o aumento de pressão dentro do sistema, uma vez que a válvula backpressure foi mantida fechada até o alcance da pressão empregada. No exato momento em que a válvula backpressure liberou a primeira fração de amostra, o sistema alcançou a pressão de trabalho e foi iniciada a contagem do tempo de extração. Em todos os experimentos a vazão foi fixada em $3 \mathrm{ml} / \mathrm{min}$. e a proporção de cossolvente, quando aplicado, em $10 \%$ do volume total de solvente. A injeção do mesmo foi modulada pelo software de controle do sistema EZ Chrome.

Para as extrações com $\mathrm{CO}_{2}$ supercrítico foram coletadas amostras de $10 \mathrm{em} 10 \mathrm{~min}$. em frascos próprios totalizando $330 \mathrm{~min}$. para as extrações a 250 bar e $170 \mathrm{~min}$. para as extrações a 300 bar. A quantificação da massa de cada frasco foi feita em balança digital semi-analítica (KN500, Digimed, Brasil). Para as extrações com $\mathrm{CO}_{2}$ e adição de cossolvente o extrato de cada corrida foi coletado em dois frascos para tempos totais variando de 60 a $180 \mathrm{~min}$. A evaporação do cossolvente foi feita em duas etapas, primeira etapa por borbulhamento de nitrogênio e segunda etapa em estufa a $50{ }^{\circ} \mathrm{C}$ com monitoramento da massa dos frascos até que atingissem peso constante, utilizando a mesma balança já citada.

\subsection{Condições Experimentais}

Os experimentos cinéticos foram executados em triplicata para cada uma das condições de 
operação. A partir dos rendimentos obtidos para cada um dos experimentos foram calculados os respectivos valores médios para cada uma das condições de operação com os quais foram construídas as curvas de extração. $O$ resultado do planejamento pode ser encontrado na Tabela 1.

Tabela 1 - Condições experimentais

\begin{tabular}{ccccc}
\hline Corrida & $\begin{array}{c}\text { Temperatura } \\
\left(\mathrm{T}^{\circ} \mathrm{C}\right)\end{array}$ & $\begin{array}{c}\text { Pressão } \\
(\text { bar })\end{array}$ & Solvente & Cossolvente \\
\hline 1 & 55 & 250 & $\mathrm{CO}_{2}$ & \\
2 & 60 & 250 & $\mathrm{CO}_{2}$ & \\
3 & 70 & 250 & $\mathrm{CO}_{2}$ & \\
4 & 55 & 250 & $\mathrm{CO}_{2}$ & Etanol \\
5 & 60 & 250 & $\mathrm{CO}_{2}$ & Etanol \\
6 & 70 & 250 & $\mathrm{CO}_{2}$ & Etanol \\
\hline 7 & 55 & 300 & $\mathrm{CO}_{2}$ & \\
8 & 60 & 300 & $\mathrm{CO}_{2}$ & \\
9 & 70 & 300 & $\mathrm{CO}_{2}$ & \\
10 & 55 & 300 & $\mathrm{CO}_{2}$ & Etanol \\
11 & 60 & 300 & $\mathrm{CO}_{2}$ & Etanol \\
12 & 70 & 300 & $\mathrm{CO}_{2}$ & Etanol \\
\hline
\end{tabular}

\subsection{Cálculo do rendimento experimental}

O rendimento experimental das extrações foi calculado com o emprego da Equação 1:

$\operatorname{Xexp}=\left(\frac{m_{g}}{m_{\text {gemsntg }}}\right) \times 100$ (Equação 1)

$m_{*}$ - Massa do extrato da semente de maracujá;

$m_{\text {gømentø }}$ - Massa total de amostra de semente do maracujá;

$X_{\exp }$ - Rendimento experimental;

\subsection{Caracterização química do extrato de maracujá}

A caracterização do perfil de ácidos graxos do extrato da semente do maracujá foi realizada no LABCAL - Laboratório de Análises do Departamento de Ciência e Tecnologia de Alimentos da Universidade Federal de Santa Catarina por cromatografia gasosa em coluna capilar, equipada com detector de ionização de chama seguindo a metodologia descrita pela AOAC conforme o método 996.06 (AOAC, 2001). 


\section{RESULTADOS E DISCUSSÕES}

As curvas de extração são apresentadas em forma de rendimento uma vez que o emprego de cossolvente não permite a construção de curvas de massa acumulada, pois, após a extração as amostras devem ser tratadas para a evaporação do solvente, o que no caso de pequenas massas pode acarretar em erros experimentais e comprometer os dados. Desta forma, os experimentos onde houve o emprego de cossolvente (ESC-EtOH) são expressos em rendimento global.

Os pontos no gráfico, referentes às curvas de extração com adição de cossolvente demonstram a ação positiva do emprego do etanol $(\mathrm{EtOH})$ para ambas as pressões empregadas, conforme mostram as Figuras 2 e 3. De forma geral, as curvas de ESC-EtOH sofreram defasagem em relação às curvas de ESC-CO $\mathrm{CO}_{2}$ no que se refere ao eixo das coordenadas. Em relação ao eixo das abscissas, as curvas de ESC-EtOH apresentaram coerência com as curvas de ESC-CO ${ }_{2}$, o que demonstra que a adição do cossolvente não impactou negativamente o rendimento da extração e reduziu significativamente o tempo necessário para atingir rendimentos próximos aos obtidos nos experimentos $\mathrm{ESC}-\mathrm{CO}_{2}$. Em geral, quando um cossolvente possui uma temperatura crítica superior à relatada para o fluido supercrítico (FSC), ocorre o aumento da solubilidade dos compostos extraíveis (Brunner, 1994). Isto confirma o observado nos experimentos, uma vez que o etanol possui temperatura crítica de $240,7^{\circ} \mathrm{C}$, valor bastante superior à temperatura crítica do dióxido de carbono, $31,1^{\circ} \mathrm{C}$.

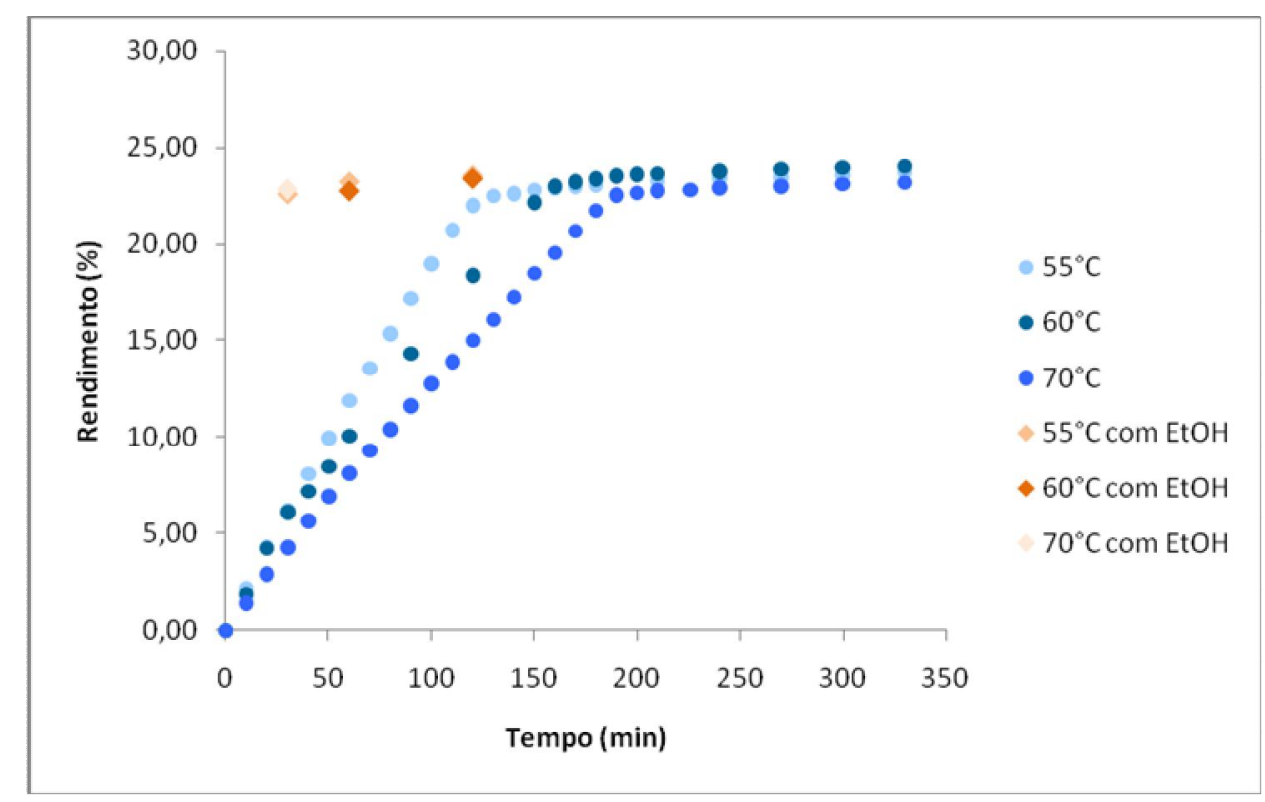

Figura 2 - Perfil de rendimento mássico em função do tempo para extrações da semente do maracujá com $\mathrm{CO}_{2}$ sob diferentes temperaturas a pressão de 250 bar na ausência e presença de cossolvente. 


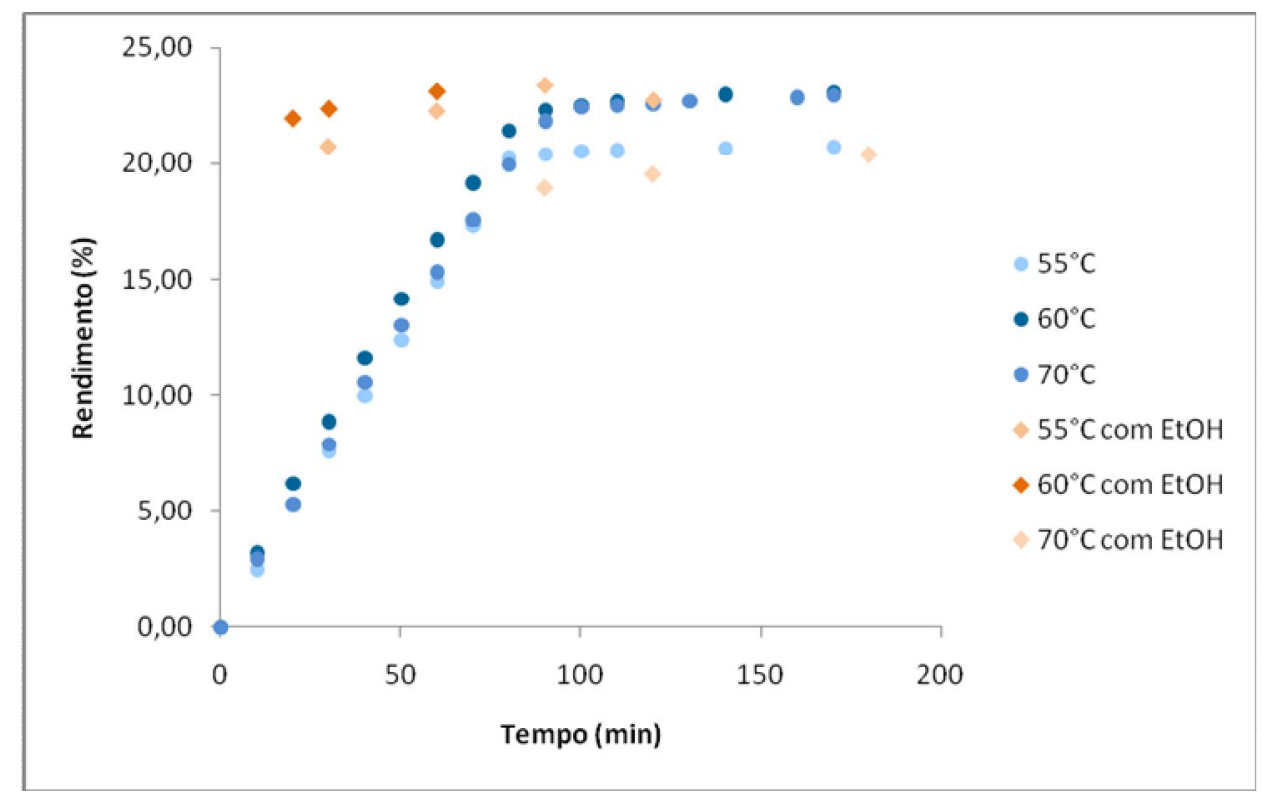

Figura 3 - Perfil de rendimento mássico em função do tempo para extrações da semente do maracujá com $\mathrm{CO}_{2}$ sob diferentes temperaturas a pressão de 300 bar na ausência e presença de cossolvente.

A análise dos rendimentos obtidos a pressão de 250 bar, que podem ser encontrados na Tabela 2 , demonstra que a adição do cossolvente foi capaz de conduzir a rendimentos aproximadamente duas vezes superiores aos obtidos por ESC-CO $\mathrm{CO}_{2}$ no tempo de $60 \mathrm{~min}$. para ambos os processos. Entretanto, em $t_{\text {final }}$ os valores de rendimento para ambos os processos atingiram patamares idênticos ou no caso do ESC- EtOH ligeiramente superiores. A 300 bar pode ser observada a mesma tendência, porém os valores de rendimento da $\mathrm{ESC}-\mathrm{EtOH}$ assumiram valores mais próximos aos obtidos por $\mathrm{ESC}-\mathrm{CO}_{2}$ devido ao efeito da pressão sobre a massa específica do $\mathrm{CO}_{2}$. Somente para a condição de $70{ }^{\circ} \mathrm{C}$ e 300 bar o comportamento descrito não foi observado, o que pode ser explicado pela ocorrência de erros experimentais. A temperatura de $70{ }^{\circ} \mathrm{C}$ foi utilizada como valor máximo de energia por ser o limite de operação do equipamento. Porém, quando empregado o cossolvente nesta temperatura ocorreram problemas operacionais relacionados ao fechamento hermético do vaso extrator, o que comprometeu os resultados a tal condição. A aceleração da velocidade de extração pode ser explicada pelo aumento da massa específica do solvente quando adicionado cossolvente ao sistema. Solventes orgânicos possuem massa específicas superiores à massa específica do $\mathrm{CO}_{2}$, o que potencializa a extração (Stievano e Elvassore, 2005).

Tabela 2 - Rendimentos experimentais das extrações de semente de maracujá por ESC-CO 2 e ESC-EtOH

\begin{tabular}{lcccccccccccc}
\hline \multirow{2}{*}{$\begin{array}{c}\text { Rendimento } \\
(\%)\end{array}$} & 1 & 2 & 3 & 4 & 5 & 6 & 7 & 8 & 9 & 10 & 11 & 12 \\
\hline & 11,9 & 10,03 & 8,13 & 23,6 & 23,48 & 23,7 & 14,9 & 16,7 & 15,3 & 23,1 & 23,3 & 19 \\
$\mathrm{t}=60$ min & 19,4 & Corrida \\
$\mathrm{t}=\mathrm{tfinal}$ & 23,7 & 23,97 & 23,1 & 23,9 & 23,26 & 23,7 & 20,7 & 23,1 & 22,9 & 23,8 & 23,4 & 20,4 \\
\hline
\end{tabular}




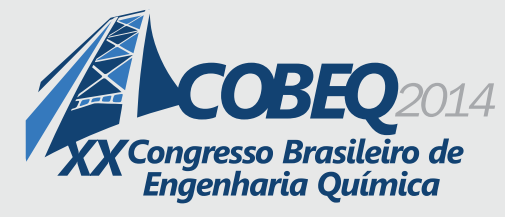

19 a 22 de outubro de 2014

Florianópolis/SC

Solventes orgânicos em pequenas quantidades combinadas com $\mathrm{CO}_{2}$ em estado supercrítico podem ainda alterar as seletividade do solvente. $\mathrm{O}$ modificador conduz a mudanças relacionadas à polaridade e interações específicas com o soluto formando pontes de hidrogênio ou mesmo interagindo com o sítio ativo da matriz sólida, de forma que as interações entre o soluto e a matriz sólida sejam quebradas e haja a substituição pelo cossolvente neste ponto da matriz. Vários estudos têm mostrado o potencial deste método para aumentar o rendimento do processo ESC-CO $\mathrm{CO}_{2}$, uma vez que o aumento da proporção EtOH - $\mathrm{CO}_{2}$ conduz a maiores solubilidades do óleo na mistura solvente. O cossolvente é capaz de alterar a solubilidade de ácido graxo (AG) no solvente beneficiando o rendimento final (Dalmolin et. al, 2010; Lui et.al., 2009). O etanol possui em sua molécula o grupo $\mathrm{OH}$, que permite a formação de pontes hidrogênio entre as moléculas deste álcool e dos compostos polares presentes nos extratos orgânicos (Lee et al., 2000). Isto explica o observado para algumas ESC-EtOH. Além de acelerar a extração em certas condições os rendimentos globais obtidos com aplicação de $10 \%$ de co-solvente foram ligeiramente superiores aos obtidos por ESC-CO $\mathrm{CO}_{2}$ como pode ser encontrado na Tabela 2.

Aproximadamente $97 \%$ do óleo do maracujá é constituído por apenas três ácidos graxos majoritários, o linoleico, principal AG presente neste óleo, oleico e palmítico como pode ser encontrado na Tabelas 3 .

Tabela 3 - Perfil de triglicerídeos do extrato da semente de maracujá determinado por CG

\begin{tabular}{|c|c|c|c|c|c|c|c|c|c|c|c|c|}
\hline \multirow{2}{*}{$\begin{array}{l}\text { Ácidos Graxos } \\
\quad(\mathrm{g} / 100 \mathrm{~g})\end{array}$} & \multicolumn{12}{|c|}{ Corrida } \\
\hline & 1 & 2 & 3 & 4 & 5 & 6 & 7 & 8 & 9 & 10 & 11 & 12 \\
\hline Araquídico (C20:0) & 0,15 & 0,16 & 0,16 & 0,16 & 0,17 & 0,16 & 0,16 & 0,16 & 0,16 & 0,16 & 0,16 & 0,18 \\
\hline Esteárico (C18:0) & 2,45 & 2,53 & 2,50 & 2,50 & 2,55 & 2,50 & 2,52 & 2,5 & 2,5 & 2,5 & 2,5 & 2,52 \\
\hline Linoleico (C18:2n 6c) & 72,00 & 72,10 & 72,24 & 72,32 & 71,92 & 72,15 & 72,34 & 72,23 & 72,17 & 72,29 & 72,37 & 71,98 \\
\hline Linolênico (C18:3n 3c) & 0,40 & 0,41 & 0,41 & 0,41 & 0,43 & 0,40 & 0,41 & 0,43 & 0,43 & 0,42 & 0,41 & 0,4 \\
\hline Oleico (C18:1n 9c) & 14,04 & 14,39 & 14,29 & 14,20 & 14,38 & 14,19 & 14,19 & 14,21 & 14,16 & 14,22 & 14,13 & 14,26 \\
\hline Palmitolêico (C16:1) & 0,18 & 0,17 & 0,17 & 0,17 & 0,17 & 0,18 & 0,17 & 0,17 & 0,18 & 0,17 & 0,17 & 0,17 \\
\hline Palmítico (C16:0) & 10,49 & 10,23 & 10,24 & 10,24 & 10,27 & 10,27 & 10,22 & 10,29 & 10,3 & 10,24 & 10,26 & 10,34 \\
\hline$\Sigma$ Saturados & 13,25 & 12,92 & 12,90 & 12,90 & 12,99 & 12,93 & 12,9 & 12,95 & 12,96 & 12,9 & 12,92 & 13,04 \\
\hline$\Sigma$ Insaturados & 86,62 & 87,07 & 87,11 & 87,10 & 87,01 & 87,08 & 87,11 & 87,04 & 87,05 & 87,1 & 87,08 & 86,97 \\
\hline
\end{tabular}

Comparando os dados apresentados na Tabelas 3 é possível observar que a adição de cossolvente, de forma geral, não causou alteração na composição de AG do óleo obtido em nenhuma das condições aplicadas. Além de reduzir significativamente o tempo de extração do óleo disponível na semente, se comparado à ESC - $\mathrm{CO}_{2}$, este não sofreu alteração em seu perfil de triglicerídeos. 


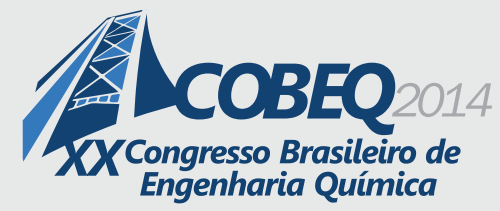

\section{CONSIDERAÇÕES FINAIS}

A adição do modificador foi capaz de promover rendimentos expressivos em menor tempo de operação. Muito provavelmente o EtOH foi capaz de beneficiar a polaridade da mistura solvente e interagir quimicamente com o sítio da matriz vegetal, acelerando o processo de obtenção do extrato. O maior rendimento obtido com adição de cossolvente, de $23,88 \%$ foi registrado à pressão de 300 bar e $55{ }^{\circ} \mathrm{C}$ após o tempo de 120 minutos. Desta forma, a aplicação do etanol beneficiou o processo de extração com $\mathrm{CO}_{2}$ supercrítico. Foram atingidas maiores taxas de extração em todas as condições de operação na presença do modificador quando comparadas as obtidas com $\mathrm{CO}_{2}$ puro. As análises cromatográficas demonstraram ainda que não ocorreram interações químicas entre modificador e extrato, uma vez que, sua utilização não alterou o perfil de ácidos graxos do extrato obtido com adição de cossolvente frente ao obtido somente com utilização de $\mathrm{CO}_{2}$ puro.

\section{REFERÊNCIAS}

AOAC. Oficial Method 996.06 Fat (Total, Saturated, and Unsaturated) in Foods: Hydrolytic extraction Gas Chromatographic Method First Action 1996, Revised 2001.

BRUNNER, G. Gas extraction: an introduction to the fundamentals of supercritical fluids and the applications to separation processes. Darmstadt, Alemanha: Steinkopff, v. 4, p.385, 1994.

CANOZZI, J. B. Avaliação do extrato da semente do maracujá (Passiflora edulis Sims) obtido por extração com dióxido de carbono supercrítico: influência do emprego de cossolvente e possíveis impactos da aplicação no processo de transesterificação com fluidos supercríticos. 2013. Dissertação (Mestrado em Engenharia Química) Universidade Federal de Santa Catarina. Florianópolis, 2013.

DALMOLIN, I.; MAZUTTI, M. A.; BATISTA, E. A. C.; MEIRELES, M. A. A.,; OLIVEIRA, J. V. Chemical characterization and phase behavior of grape seed oil in compressed carbon dioxide and ethanol as a co-solvent. J. Chem. Thermodynamics, v. 42; p. 797-801, 2010.

FERRARI, R. A.; COLUSSI, F.; AYUB, R. A. Caracterização de subprodutos da industrialização do maracujá - aproveitamento das sementes. Revista Brasileira de Fruticultura, v. 26, p. 101-202, 2004.

JORGE, N.; KOBORI, N. C. Caracterização dos óleos de algumas sementes de frutas como aproveitamento de resíduos industriais. Ciência Agrotecnologia, v. 29, n. 5,p. 1008,1014, 2005.

LEE, W. Y.; CHO, Y. J.; OH, S. L.; PARK, J. H.; CHA, W. S.; JUNG, J. Y.; CHOI, Y. H. Extraction of grape seed oil by supercritical $\mathrm{CO}_{2}$ and ethanol modifier. Food Science Biotechnology.v. 93, p. 174-178, 2000.

LIU, S.; YANG, F;. ZHANG, C.; JI, H.; HONG, P.; DENG, C. Optimization of process parameters for supercritical carbon dioxide extraction of Passiflora seed oil by response surface methodology. The Journalof Supercritical Fluids, v.48, p. 9-14, 2009.

STIEVANO, M.; ELVASSORE, N. High-pressure density and vapour-liquid equilibrium for the binary systems carbon dioxide-ethanol, carbon dioxide-acetone and carbon dioxidedichloromethane.The Journal of Supercritical Fluids, v. 33, p. 7-14, 2005. 